\title{
Mechanical activation of polymers containing two adjacent mechanophores
}

DOI:

10.1039/DOPY00279H

\section{Document Version}

Accepted author manuscript

Link to publication record in Manchester Research Explorer

\section{Citation for published version (APA):}

Stevenson, R., Zhang, M., \& De Bo, G. (2020). Mechanical activation of polymers containing two adjacent mechanophores. Polymer Chemistry. https://doi.org/10.1039/DOPY00279H

\section{Published in:}

Polymer Chemistry

\section{Citing this paper}

Please note that where the full-text provided on Manchester Research Explorer is the Author Accepted Manuscript or Proof version this may differ from the final Published version. If citing, it is advised that you check and use the publisher's definitive version.

\section{General rights}

Copyright and moral rights for the publications made accessible in the Research Explorer are retained by the authors and/or other copyright owners and it is a condition of accessing publications that users recognise and abide by the legal requirements associated with these rights.

\section{Takedown policy}

If you believe that this document breaches copyright please refer to the University of Manchester's Takedown Procedures [http://man.ac.uk/04Y6Bo] or contact uml.scholarlycommunications@manchester.ac.uk providing relevant details, so we can investigate your claim.

\section{OPEN ACCESS}




\title{
ARTICLE
}

\section{Mechanical activation of polymers containing two adjacent mechanophores}

Received 00th January 20xx Accepted 00th January 20xx DOI: $10.1039 / \times 0 \times x 00000 x$

\begin{abstract}
Richard Stevenson ${ }^{a}$, Min Zhang ${ }^{a}$ and Guillaume De Bo ${ }^{* a}$
Mechanophore activation is usually performed on chain-centred or multi-mechanophore polymers. Here we investigate the activation of a bis-mechanophore system where two identical Diels-Alder adduct mechanophores are joined together with a short linker. Although CoGEF calculations suggest that the presence of a mechanophore affects the mechanochemical coupling of an adjacent mechanophore, we found no difference in the scission rate between various bis-mechanophore systems and their respective mono-mechanophore reference when activated by ultrasound in solution.
\end{abstract}

\section{Introduction}

In polymer mechanochemistry, polymer chains are used to deliver mechanical force to mechanosensitive groups called mechanophores. ${ }^{1,2}$ This process is usually achieved by one of two polymer architectures: a chain-centred system, whereby a single mechanophore is embedded in the centre of a polymer chain $^{3}$ (Figure 1a), or a multi-mechanophore system, where the entire polymer consists of mechanophores linked together (Figure 1b). ${ }^{4}$ These architectures have been used to uncover the impact of the linker structure, ${ }^{5-10}$ which can be used to manipulate the mechanochemical coupling, and the mechanophore geometry, ${ }^{11-19}$ where the connectivity with th actuating polymer dramatically impact the mechanochemical coupling, on the mechanical activity of a mechanophore. However, little is known on how the presence of a mechanophore affects the activation of an adjacent mechanophore. ${ }^{20}$ During our investigation of the mechanochemistry of the mechanical bond, 5,21-23 we have found that a mechanophore could be protected from mechanical force when embedded in the ring of a catenane, ${ }^{23}$ and that the use of a rotaxane as a force actuator can slow the activation of a mechanophore embedded in its axle by creating a competing high-stress region (i.e. another bond being significantly elongated) where the axle is deformed by the macrocycle. ${ }^{5}$ Based on this latter observation, we hypothesised that two mechanophores in close proximity should affect each other's mechanical activation due to the presence of two competing elongating bonds. Here we investigate the mechanical activation of polymers containing two adjacent Diels-Alder (DA) adduct mechanophores ${ }^{12}$ in various geometries. We found that despite a difference in calculated mechanochemical coupling observed between the bismechanophore polymers and their mono-mechanophore

a. Department of Chemistry, University of Manchester, Oxford Road, Manchester M13 9PL, United Kingdom.E-mail: guillaume.debo@manchester.ac.uk Electronic Supplementary Information (ESI) available: [details of any supplementary information available should be included here]. See DOI: 10.1039/x0xx00000x counterparts, all the investigated systems cleaved at a similar rate upon ultrasound activation.

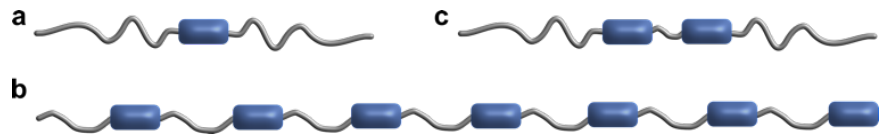

Figure 1. Common polymer architectures used for mechanophore activation involve chain-centred mechanophore (a) and multi-mechanophore chains (b). Here we investigate chain-centred bis-mechanophore systems (c).

\section{Results and discussion}

We investigated a series of polymers functionalised with either one $(\mathbf{1}, \mathbf{5}, \mathbf{7})$ or two $(\mathbf{2 - 4}, \mathbf{6})$ DA mechanophores at the centre point (Figure 2a), by varying the nature of the linker or the relative orientation of the mechanophores. We used the proximal-exo isomer (blue) of our previously described furan/maleimide DA adduct as the mechanically active unit (Figure 2b). To ensure a fair comparison, in polymers functionalised with only one mechanophore, the active mechanophore was linked to its mechanically inert distal-exo counterpart (green). ${ }^{12}$ Small changes in geometry can have large effects on mechanical activation, ${ }^{11-19}$ thus, investigating different orientations of tethered mechanophores allows us to explore deviations in mechanical activity due to linker structure. Proximal-exo mechanophores were tethered through the maleimide units using alkyl (2) or glutaric (3) linkers. Additionally, the two DA adducts were linked in three different relative orientations: head-to-head $(\mathrm{HtH}, 2-3)$, tail-to-tail (TtT, 4-5), and head-to-tail (HtT, 6-7), where the nitrogen of the maleimide and the double bond of the furan are referred to as head and tail units respectively. Polymers containing two active mechanophores are referred to as homo-dimers and those containing both active and inactive adducts as hetero-dimers. These varied combinations were also compared to reference compound 1, which contains a single active DA unit with the glutaric linker bound directly to the force-transducing polymer. 
The desired bis-mechanophore units were synthesised by successively connecting the desired DA adducts to the glutaric acid linker (See SI for details). Polymers were prepared from bifunctional initiators $\mathbf{1 - 7 b}$ via SET-LRP24 of methyl acrylate to prepare centre-functionalised PMA with a $M_{\mathrm{n}}$ range of 51.1$58.6 \mathrm{kDa}$ (Table 1). The relatively narrow range of $M_{\mathrm{n}}$ obtained allows for the direct comparison of their rates of cleavage.

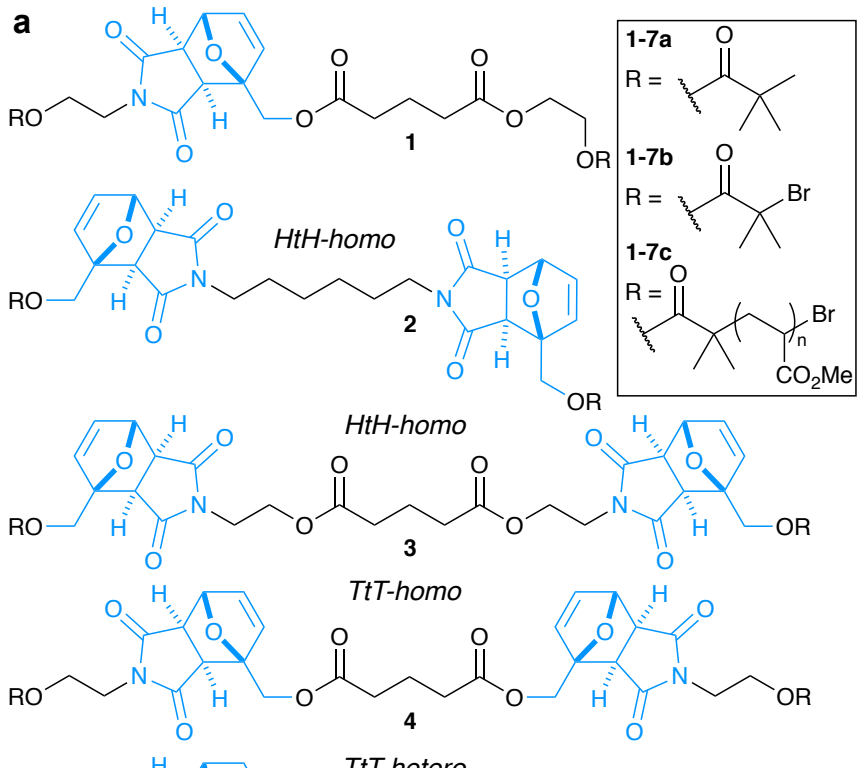

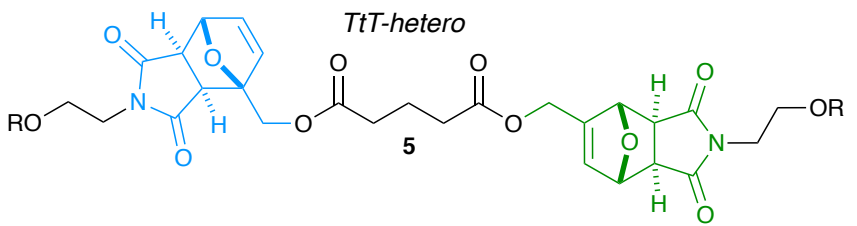

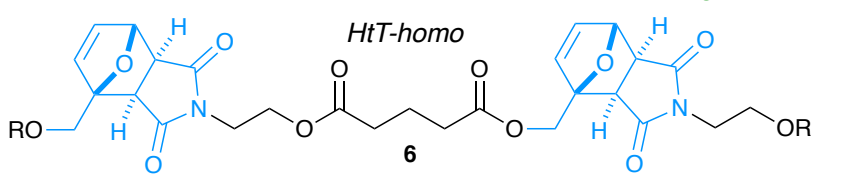

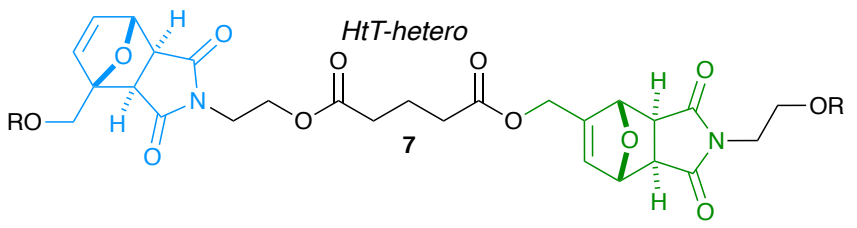

b

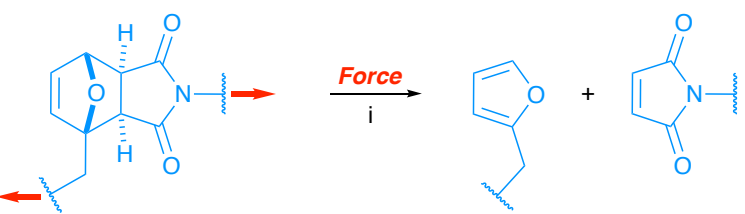

Figure 2. (a) Structures of the adducts used in this study of mechanophores in close proximity, along with labels indicating their geometries. The nitrogen of the maleimide and double bond of the furan are considered the head and tail units respectively. Therefore: $\mathrm{HtH}=$ head-to-head, $\mathrm{TtT}=$ tail-to-tail and $\mathrm{HtT}=$ head to tail. (b) Force-accelerated retro-Diels-Alder reaction investigated in this study. Conditions: (i) Ultrasound ( $\left.20 \mathrm{kHz}, 11.7 \mathrm{~W} / \mathrm{cm}^{2}, 1 \mathrm{~s} \mathrm{ON} / 2 \mathrm{~s} \mathrm{OFF}\right), \mathrm{CH}_{3} \mathrm{CN}, 5-10^{\circ} \mathrm{C}$.
Table 1. Molecular weight and rate of mechanical cleavage of the mechanophorecentred polymers 1-7c. ${ }^{\text {a }}$ Determined from the slope of the linear fit in Figure 6.

\begin{tabular}{clccc}
\hline Polymer & Geometry & $\boldsymbol{M}_{\mathbf{n}}$ (kDa) & $\boldsymbol{\theta}$ & $\boldsymbol{k}^{*}\left(\mathbf{k D a}^{-1} \cdot \mathbf{m i n}^{-1} \mathbf{. 1 0 ^ { 5 }}\right)^{\mathbf{a}}$ \\
\hline 1c & reference & 58.6 & 1.14 & 6.41 \\
2c & HtH-homo & 51.1 & 1.22 & 6.59 \\
3c & HtH-homo & 52.7 & 1.16 & 6.33 \\
4c & TtT-homo & 53.8 & 1.18 & 5.39 \\
5c & TtT-hetero & 54.1 & 1.19 & 5.65 \\
6c & HtT-homo & 55.8 & 1.19 & 6.31 \\
7c & HtT-hetero & 53.4 & 1.29 & 5.90 \\
\hline
\end{tabular}

The mechanical activation of tethered mechanophores 1-7c was performed by subjecting dilute solutions of the polymers to high-intensity ultrasound (Figure $2 \mathrm{~b}$ ). Solutions of polymers 17c in acetonitrile $(\sim 1 \mathrm{mg} / \mathrm{mL})$ were sonicated at low temperature $\left(5-10^{\circ} \mathrm{C}\right)$ with a high-intensity probe $(20 \mathrm{kHz}, 11.7$ $\mathrm{W} / \mathrm{cm}^{2}$, 1s ON/2s OFF). ${ }^{1} \mathrm{H}$ NMR analysis of each sonicated polymer confirms that a single dissociation occurs via a retroDiels-Alder (rDA) pathway (Figures 3-5). In the case of $\mathrm{HtH}$ polymers 2-3c the appearance of the aromatic signals of furanterminated PMA $8 \mathrm{c}\left(\mathrm{H}_{1}, 7.40 \mathrm{ppm} ; \mathrm{H}_{2} / \mathrm{H}_{3}, 6.35 \mathrm{ppm}\right)$ is indicative of a dissociation via a rDA reaction (Figure 3 ).

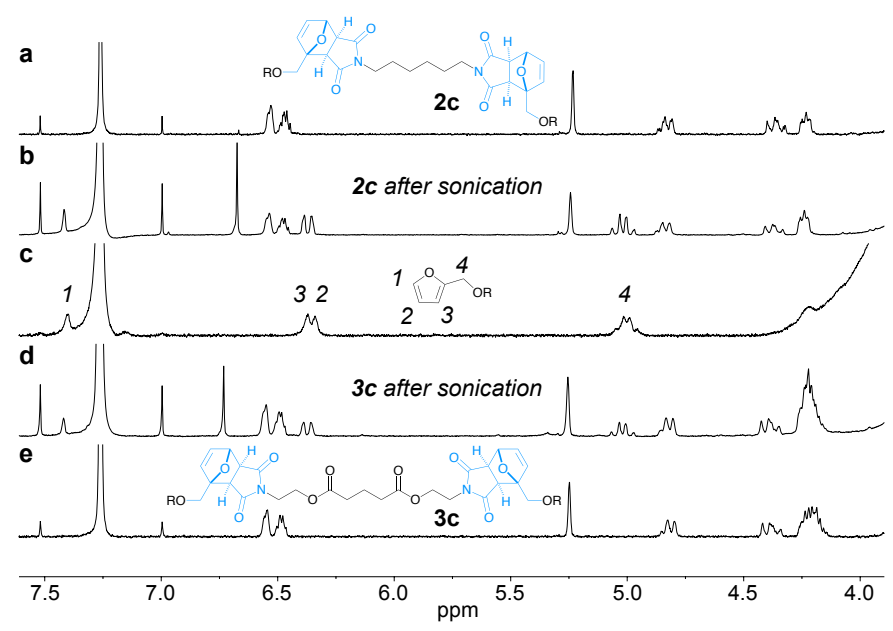

Figure 3. Partial ${ }^{1} \mathrm{H}$ NMR $\left(400 \mathrm{MHz}, \mathrm{CDCl}_{3}\right)$ of $\mathrm{HtH}$ polymer $2 \mathrm{c}(\mathrm{a})$ before and (b) after sonication ( $240 \mathrm{~min}$ ), and $\mathrm{HtH}$ polymer $\mathbf{3 c}$ (e) before and (d) after sonication (240 $\mathrm{min}$ ), along with reference polymer $8 \mathrm{c}$ (c).

Similarly, in TtT adducts $\mathbf{4 c}$ and $\mathbf{5 c}$, where the DA units are linked via the furan sites, the appearance of the characteristic maleimide olefinic signal $\left(H_{a}, 6.72 \mathrm{ppm}\right)$ indicates a rDA dissociation pathway (Figure 4). 


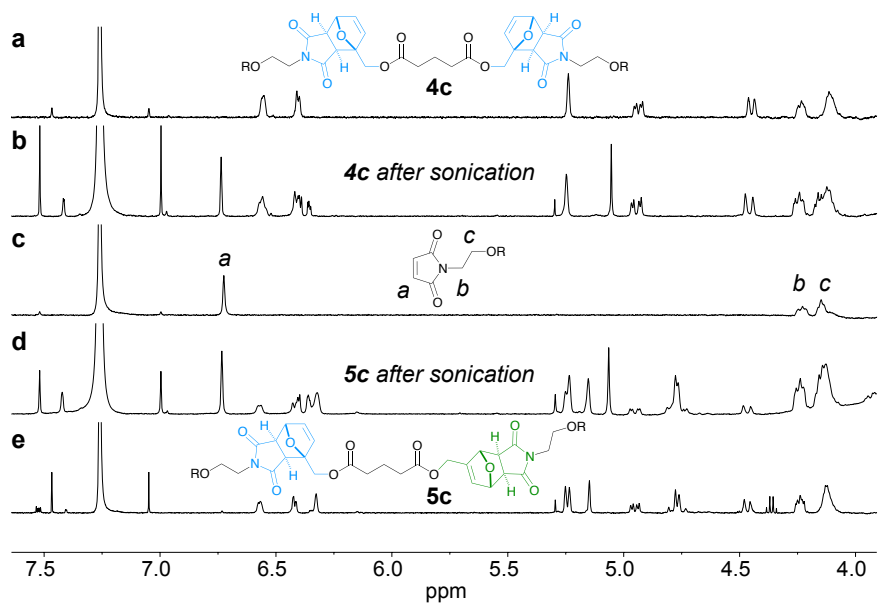

Figure 4. Partial ${ }^{1} \mathrm{H}$ NMR $\left(400 \mathrm{MHz}, \mathrm{CDCl}_{3}\right)$ of polymer $3 \mathrm{c}(\mathrm{a})$ before and (b) after sonication ( $240 \mathrm{~min}$ ), and polymer $\mathbf{6 c}$ (e) before and (d) after sonication ( $240 \mathrm{~min}$ ), along with reference polymer $9 \mathrm{c}$ (c)

In HtT-hetero polymer 7c, cleavage should only occur at the proximal-exo site and so the expected product would be furanterminated polymer $\mathbf{8 c}$. This is indeed the case with the characteristic furan signals appearing in the post-sonication spectrum (Figure 5c,e-f).

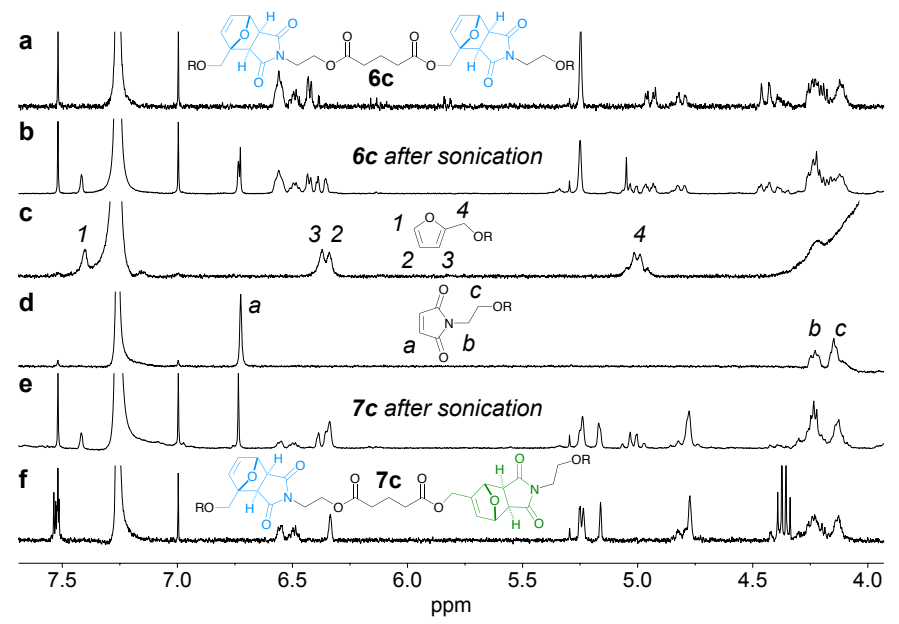

Figure 5. Partial ${ }^{1} \mathrm{H}$ NMR $\left(400 \mathrm{MHz}_{2} \mathrm{CDCl}_{3}\right)$ of polymer $3 \mathrm{c}(\mathrm{a})$ before and (b) after sonication ( $240 \mathrm{~min}$ ), and polymer $\mathbf{6 c}$ (e) before and (d) after sonication ( $240 \mathrm{~min}$ ), along with reference polymers $8 \mathrm{c}$ and $9 \mathrm{c}$ (c).

Cleavage via a rDA pathway can occur at either end of HtT homo-dimer $\mathbf{6 c}$ and would lead to either furan- or maleimidecapped PMA as products. Interestingly, the doubling of the furan aromatic protons $\left(\mathrm{H}_{1}-\mathrm{H}_{3}\right)$ and the maleimide double bond protons $\left(\mathrm{H}_{\mathrm{a}}\right)$ suggests cleavage is occurring at both sites (Figure $5 a-d)$. This is affirmed by the two signals seen in the maleimide double bond region ( 6.70-6.75 ppm), whereby one signal is coming from maleimide-capped PMA, indicating cleavage at the right-hand DA adduct, and the other from the product of cleavage at the left-hand adduct. Therefore, all mechanophores in this study are undergoing force-facilitated cleavage via a rDA pathway.
The evolution of the sonication reaction was monitored by SEC and modelled as first order using the Nalepa method ${ }^{25}$ to calculate the relative rate of degradation. Each polymer underwent five sonication experiments and the average of the relative rates across these runs covered a range of values from 5.39-6.59 $\mathrm{kDa}^{-1} \cdot \mathrm{min}^{-1} \cdot 10^{5}$ (Table 1). Statistical analysis, performed by one-way ANOVA followed by Tukey's multiple comparisons test using Graphpad Prism version 8.2.0 for Windows, did not reveal any clear association between rate of cleavage and the presence of a second mechanophore. A lack of significant pattern in mechanical activity of 1-7c can be seen when looking at the overlay of the degradation kinetics (Figure 6). As a result, neither the presence of another mechanophore, nor the nature of the linker or the relative orientation of the mechanophore units had an impact on the rate of mechanical dissociation in the conditions investigated.

The energy/elongation curves of adducts 1-7a, obtained by CoGEF calculations (DFT B3LYP/6-31G*), ${ }^{26}$ present a narrow distribution of $F_{\max }$ values ranging from 3.56-3.80 nN (Table 2 and Figure 7a). In contrast, the mechanochemical coupling seems to show a pattern of lower values for bis-mechanophores compared to their single mechanophore counterparts (Figure 7b).

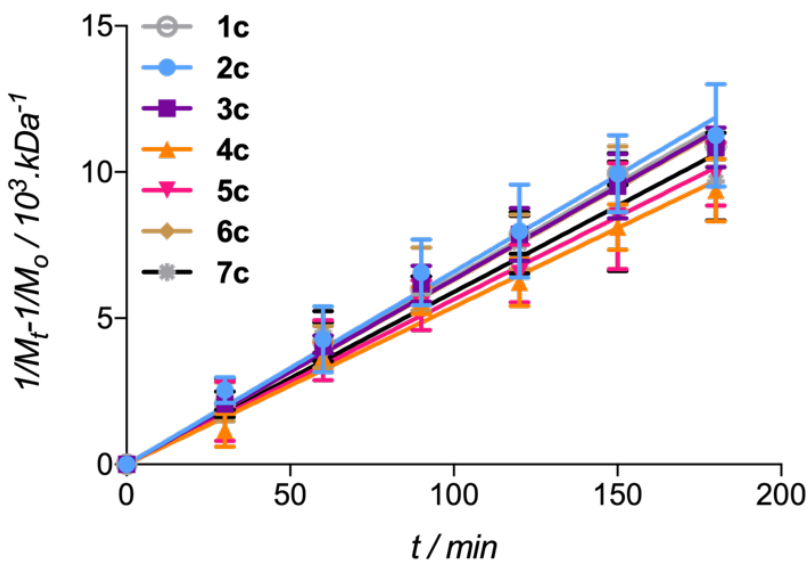

Figure 6. Mechanical activation of polymers 1-7c. Changes in $M_{n}$ determined by SEC. Conditions: ultrasound ( $20 \mathrm{kHz}, 11.7 \mathrm{~W} / \mathrm{cm}^{2}, 1 \mathrm{~s} \mathrm{ON} / 2 \mathrm{~s}$ OFF), $\mathrm{CH}_{3} \mathrm{CN}, 5-10^{\circ} \mathrm{C}$. Solid lines correspond to a linear fit $\left(R^{2}=0.993,0.988,0.992,0.984,0.993,0.986\right.$, and 0.958 for 1 7c respectively). Each point corresponds to the average over 5 experiments. Error bars represent the standard deviation. 
a

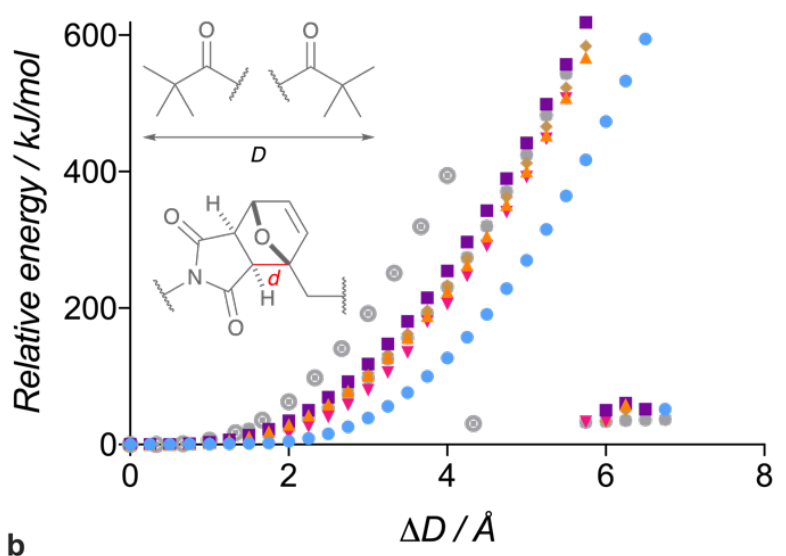

b

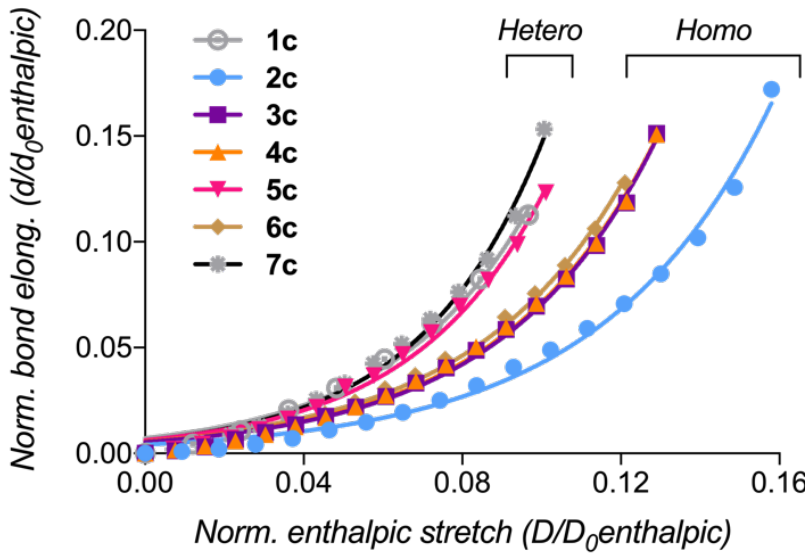

Figure 7. Evolution of energy (a) and mechanochemical coupling (b) of 1-7a upon simulated elongation (COGEF, DFT B3LYP/6-31G*). The enthalpic stretch is defined as the section of the elongation profile where $\Delta \mathrm{d}$ is repeatedly $\geq 0.001$. translated into a reduced rate of activation. In the bismechanophore systems investigated here, we anticipated a reduction in rate due to two mechanophores sharing the overall stress at separate sites. A difference in mechanochemical coupling is indeed observed between bis-mechanophores and single mechanophores in the CoGEF calculation (Figure 7b). However, this difference didn't translate into an observable impact on the activation rate (Figure 6). It should be noted that the differences in coupling observed here are smaller than the differences calculated for the rotaxane system, ${ }^{5}$ and it is possible that a more sensitive technique could uncover such subtle differences. ${ }^{14,16}$ Perhaps more significant, the presence of a second identical mechanophore provides a second site with an equal probability of cleavage. This effect might compensate for the reduced coupling.

\section{Conclusions}

We set out to investigate the mechanical activation of polymers containing two mechanophores linked together in the centre of the chain. A set of tethered mechanophores with different linkers and relative orientations were investigated. A lower mechanochemical coupling was observed for the bismechanophore system compared to the mono-adducts in the CoGEF calculations, suggesting that the presence of a mechanophore could affect the activation of an adjacent mechanophore. However, no statistically significant differences in the rate of mechanophore cleavage could be observed upon ultrasound activation. This effect could be too subtle to produce an observable difference in the sonication kinetics and/or due to the fact that the presence of a second mechanophore provides a second site with an equal probability of cleavage.

\section{Conflicts of interest}

There are no conflicts to declare.

\section{Acknowledgements}

We thank the EPSRC for a studentship to R.S. (NOWNANO-CDT) and the Royal Society for a Newton International Fellowship to M.Z. and a University Research Fellowship to G.D.B.

\section{Notes and references}

1 M. M. Caruso, D. A. Davis, Q. Shen, S. A. Odom, N. R. Sottos, S. R. White and J. S. Moore, Chem. Rev., 2009, 109, 57555798.

2 M. K. Beyer and H. Clausen-Schaumann, Chem. Rev., 2005, 105, 2921-2948.

3 J. Li, C. Nagamani and J. S. Moore, Acc. Chem. Res., 2015, 48, 2181-2190.

$4 \quad$ B. Bowser and S. L. Craig, Polym. Chem., 2018.

5 M. Zhang and G. De Bo, J. Am. Chem. Soc., 2018, 140, 1272412727. 
6

J. Wang, T. B. Kouznetsova, Z. S. Kean, L. Fan, B. D. Mar, T. J. Martinez and S. L. Craig, J. Am. Chem. Soc., 2014, 136,

15162-15165.

7 H. M. Klukovich, T. B. Kouznetsova, Z. S. Kean, J. M. Lenhardt and S. L. Craig, Nat. Chem., 2013, 5, 110-114.

8 Y. Tian and R. Boulatov, ChemPhysChem, 2012, 13, 22772281.

$9 \quad$ H. M. Klukovich, Z. S. Kean, A. L. B. Ramirez, J. M. Lenhardt, J. Lin, X. Hu and S. L. Craig, J. Am. Chem. Soc., 2012, 134, 95779580.

10 J. Ribas Arino, M. Shiga and D. Marx, J. Am. Chem. Soc., 2010, 132, 10609-10614.

11 Y. Lin, M. H. Barbee, C.-C. Chang and S. L. Craig, J. Am. Chem. Soc., 2018, 140, 15969-15975.

12 R. Stevenson and G. De Bo, J. Am. Chem. Soc., 2017, 139, 16768-16771.

13 M. J. Robb, T. A. Kim, A. J. Halmes, S. R. White, N. R. Sottos and J. S. Moore, J. Am. Chem. Soc., 2016, 138, 12328-12331.

14 G. R. Gossweiler, T. B. Kouznetsova and S. L. Craig, J. Am. Chem. Soc., 2015, 137, 6148-6151.

15 S. S. M. Konda, J. N. Brantley, B. T. Varghese, K. M. Wiggins, C. W. Bielawski and D. E. Makarov, J. Am. Chem. Soc., 2013, 135, 12722-12729.

16 Z. Wang and S. L. Craig, Chem. Commun., 2019, 50, 2836.

17 H. Zhang, X. Li, Y. Lin, F. Gao, Z. Tang, P. Su, W. Zhang, Y. Xu, W. Weng and R. Boulatov, Nat. Commun., 2017, 8, 1147.

18 R. Groote, B. M. Szyja, F. A. Leibfarth, C. J. Hawker, N. L. Doltsinis and R. P. Sijbesma, Macromolecules, 2014, 47, 1187-1192.

19 M. J. Kryger, A. M. Munaretto and J. S. Moore, J. Am. Chem. Soc., 2011, 133, 18992-18998.

20 J. M. Lenhardt, J. W. Ogle, M. T. Ong, R. Choe, T. J. Martinez and S. L. Craig, J. Am. Chem. Soc., 2011, 133, 3222-3225.

21 M. Zhang and G. De Bo, J. Am. Chem. Soc., 2019, 141, 1587915883.

22 G. De Bo, Chem. Sci., 2018, 9, 15-21.

23 M. Zhang and G. De Bo, J. Am. Chem. Soc., 2020, 142, 50295033.

24 A. Anastasaki, V. Nikolaou, G. Nurumbetov, P. Wilson, K. Kempe, J. F. Quinn, T. P. Davis, M. R. Whittaker and D. M. Haddleton, Chem. Rev., 2016, 116, 835-877.

25 T. Sato and D. E. Nalepa, J Appl Polym Sci, 1978, 22, 865-867.

26 M. Beyer, J. Chem. Phys., 2000, 112, 7307-7312. 